\title{
Pattern of fine needle aspiration cytology of superficially palpable lesions: One year hospital based study
}

\author{
Piya $E^{1}$, Panth $\mathbf{R}^{1}$, Singh $\mathbf{S}^{1}$ \\ ${ }^{1}$ Consultant pathologists, Pathology Department, Shree Birendra Hospital C hhauni
}

\begin{abstract}
Introduction: This is a retrospective study on fine needle aspiration cytology (FNAC) of superficially palpable lesions done in Shree Birendra Hospital, C hhauni, over a period of one year from $14^{\text {th }} \mathrm{April} 2008$ to $13^{\text {th }}$ April 2009.
\end{abstract}

Aim: The aim of this study was to review cytlogical diagnosis on superficially palpable lesions in various sites.

Methods: A total of 323 cytological diagnoses of palpable lumps performed in one year by pathologists were retrieved. Sites of FNA and diagnoses were analyzed and correlated with age and sex of the patients.

Results:This study has included 323 FNACs. Lymph node was the most common site for FNAC (32\%), followed by breast $(29 \%)$, thyroid $(22 \%)$, and salivary gland $(2 \%)$. Other site comprised $15 \%$ of cases. In lymph node, reactive lymphadenitis was the most common benign lesion $(42.7 \%)$ and metastatic squamous cell carcinoma was the commonest malignant lesion(12.62\%). In breast, benign proliferative breast disease was the most common(84.1\%) and ductal carcinoma was commonest among malignant lesions (8.5\%). Among thyroid lesions, benign proliferative thyroid disease was the commonest one (47.9\%)followed by papillary carcinoma among malignant lesions(11.3\%).Among salivary gland lesions, chronic sialadenitis was most common inflammatory lesion (37.5\%)followed by pleomorphic adenoma among benign lesions $(25 \%)$ and carcinoma comprised $25 \%$. Lipoma was the commonest lesion ( $63 \%$ ) from other sites.

Conclusion: Wide range of lesions, both benign and malignant, can be diagnosed by FNAC thus restricting surgery to cases only requiring further histopathological evaluation.

\section{Introduction}

Fine needle aspiration cytology (FNAC) is a diagnostic procedure used to investigate easily papable superficial lumps or masses in organs like thyroid, breast, lymph nodes, and salivary glands. Modern imaging techniques mainly ultrasonography(USG) and computed tomography (CT) guided FNA are carried out on those lesions not easily palpable and located in deeper areas and organs such as lungs, mediastinum and abdominal, retroperitoneal and pelvic regions 1,2 . FNAC is safer and less traumatic, relatively painless with speedy result and cheap. Major complications are usually rare ${ }^{3}$. Common complications include bruising and soreness. Its accuracy in many situations, when applied by experienced and well trained pathologists, can approach that of histopathology in providing workable diagnosis. However, aspiration cytology is not a substitute for surgical histopathology. Instead it should be regarded as a very important preoperative/ pretreatment investigation. False negative results may sometimes be obtained because of low cell yield or sampling error. A definitive diagnosis may not always be possible in conditions with haemorrahge, infarction and reparative changes which at times mimic neoplastic features ${ }^{1}$. Therefore information obtained by FNAC must always be correlated with clinical features and relevant investigations.

\section{Aim}

The main aim of this study is to analyze different cytological diagnoses of superficially palpable lumps on FNAC.

\section{Material And Method}

A total of 323 cytological diagnoses of palpable lumps performed in one year by pathologists were retrieved. Sites of FNA and diagnoses were analyzed and correlated with age and sex of the patients.

CT/USG guided FNA done from deeper areas and organs such as lungs, mediastinum and abdominal, retroperitoneal and pelvic organs and tissues were excluded from this study.

\section{Results}

A total of 323 FNA were done from various sites. The various sites and their and percentages are shown in the pie chart.

Address for correspondence: evapiya@yahoo.com 


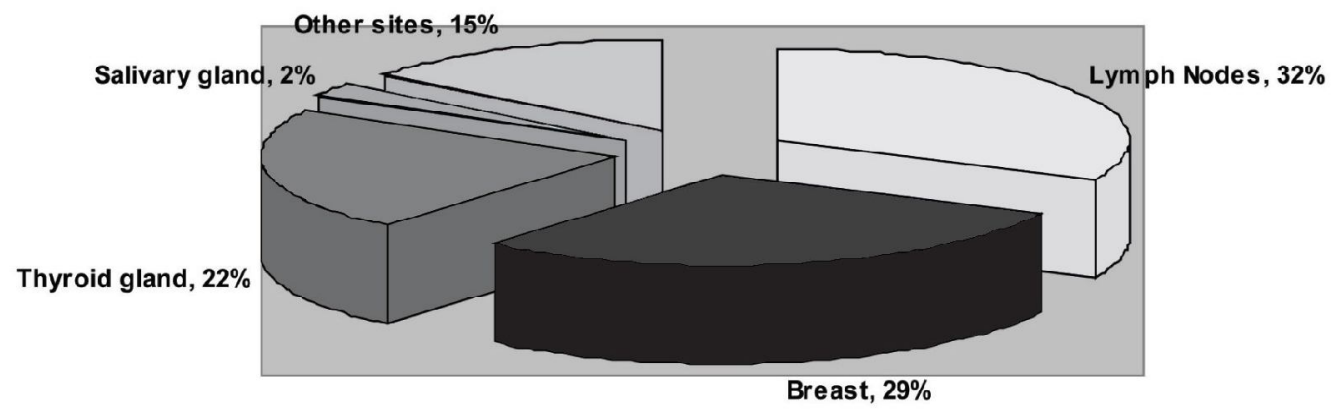

There were a total $268(83 \%)$ benign and 55 malignant cases (17\%) as depicted in the pie chart.

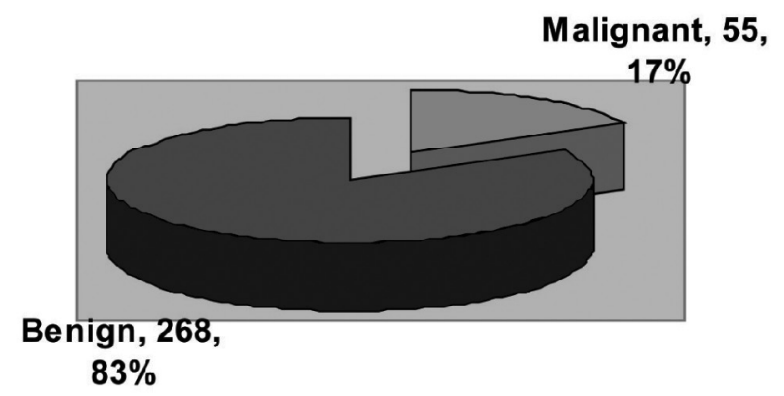

\section{Lymph Nodes}

103 FNAC were done from enlarged lymph nodes, 44 of which were reported as reactive lymphadenitis, 26 as granulomatous lymphadenitis. 33 cases were diagnosed to have malignancy. Metastatic malignancy was more common than lymphoma $(2.9 \%)$ Cervical lymph was the most common site $(85 \%)$.

\begin{tabular}{|l|c|c|}
\hline \multicolumn{1}{|c|}{ FNAC Diagnosis } & Number & Percentage(\%) \\
\hline Reactive Lymphadenitis & 44 & 25.72 \\
\hline Granulomatous Lymphadenitis & 26 & 12.60 \\
\hline Metastatic Squamous Cell Carcinoma & 13 & 2.92 \\
\hline Lymphoma & 3 & 3.90 \\
\hline Metastatic Adenocarcioma & 4 & 3.90 \\
\hline Metastatic Malignant melanoma & 4 & 2.90 \\
\hline Metastatic Small Cell Carcinoma & 3 & 2.90 \\
\hline Positive for malignant Cells & 3 & 0.97 \\
\hline Metastatic Hepatocellular Carcinoma & 1 & 0.97 \\
\hline MetastaticPapillary Carcinoma & 1 & 0.97 \\
\hline Metastatic Clear cell carcinoma & 1 & 100 \\
\hline Total & 103 & \\
\hline
\end{tabular}

Reactive and granulomatous lymphadenitis were seen relatively in younger age group (mean age 23years) whereas mean age was 46 years for malignant cases. Male -to -female ratio was 3:1 in malignant cases. 


\section{Breast}

A total of 94 FNAs were done from breast. Various lesions diagnosed on FNA are tabulated as follows.

Breast was the second common site for FNAC. Benign proliferative breast disease was the commonest lesion in the age group of 20 to $45 y e a r s$. Among malignant lesions, which favoured patients above 50years of age ductal carcinoma was the commonest (88\%). Male - to-female ratio was 1:8 in case of malignant lesions.

\begin{tabular}{|l|c|c|}
\hline \multicolumn{1}{|c|}{ FNAC Diagnosis } & Number & Percentage(\%) \\
\hline Benign Proliferative Breast Disease & 79 & $84 . .1$ \\
\hline Gynaecomastia & 4 & 4.2 \\
\hline Ganulomatous Lesion & 2 & 2.1 \\
\hline Ductal Carcinoma & 8 & 8.5 \\
\hline Lobular carcinoma Total & 1 & 1.1 \\
\hline \multicolumn{2}{c|}{$\quad 94$} & 100 \\
\hline
\end{tabular}

\section{Thyroid Gland}

Out of 71 thyroid lesions, 63 were benign and 8 were malignant. cases. Benign proliferative thyroid disease was the commonest $(54.9 \%)$ lesion followed by colloid goitre $(23.2 \%)$. Papillary carcinoma was the most common malignant lesion (11.3\%). Male to female ratio was 1:8 in case of malignant lesions and the mean age was $26 y e a r s$.

\begin{tabular}{|l|c|c|}
\hline \multicolumn{1}{|c|}{ FNA Diagnosis } & Number & Percentage (\%) \\
\hline Benign Proliferative Thyroid Disease & 34 & 47.9 \\
\hline Colloid Goitre & 17 & 23.2 \\
\hline Subacute Thyroiditis & 4 & 5.7 \\
\hline Lymphocytic Thyroiditis & 3 & 4.2 \\
\hline Hashimoto Thyroiditis & 3 & 4.2 \\
\hline Thyroglossal Cyst & 1 & 1.4 \\
\hline Follicular adenoma & 1 & 1.4 \\
\hline Papillary Carcinoma & 8 & 11.3 \\
\hline \multicolumn{1}{|c|}{ Total } & 71 & 100 \\
\hline
\end{tabular}

\section{Salivary G land}

Various salivary gland lesions diagnosed on FNAC are listed below. The most common site for FNAC was parotid gland. $25 \%$ of total cases was found to be malignant. Male-to-female ratio in case of malignancy was 1:1.

\begin{tabular}{|l|c|c|}
\hline \multicolumn{1}{|c|}{ FNA Diagnosis } & Number & Percentage(\%) \\
\hline Chronic Sialoadenitis & 3 & 25 \\
\hline Pleomorphic Adenoma & 2 & 12.5 \\
\hline Benign salivary Lesion & 1 & 12.5 \\
\hline Mucoepidemoid Carcinoma & 1 & 12.5 \\
\hline Hyalinizing Clear Cell Carcinoma & 1 & 100 \\
\hline Total & 8 & 25 \\
\hline
\end{tabular}




\section{Other Sites}

Out of 47 FNA done from other palpable lumps, lipoma was the commonest benign lesion, with malignant melanoma being the commonest of two malignant cases.

\begin{tabular}{|c|c|c|}
\hline FNA Diagnosis & Number & Percentage(\%) \\
\hline Lipoma & 30 & 63.7 \\
\hline Haemangioma & 4 & 8.6 \\
\hline Keratinous Cyst & 4 & 6.6 \\
\hline Neurofibroma & 3 & 6.4 \\
\hline Paraganglioma & 3 & 4.3 \\
\hline Malignant Melanoma & 2 & 2.1 \\
\hline Fibromyxoid Sarcoma & 1 & 100 \\
\hline Total & 47 & 2 \\
\hline
\end{tabular}

\section{Discussion}

FNAC contributes significantly to preoperative investigations in patients with palpable lumps. Its importance in detecting cancer is widely recognized ${ }^{2}$ . Out of 323 FNACs, $83 \%$ of lesions were benign and $17 \%$ were malignant.

The most common site of FNAC was lymph node $(32 \%)$. Reactive lymphadenitis was the most common lesion(42.72\%) followed by granulomatous lymphadenitis $(25.25 \%)$. This is similar to the study done by Haque MA et al in which cervical lymph node was the commonest site $(87 \%)$. 4. This matched with our experience $(85 \%)$. In his study, reactive lymphadenitis comprised $27.1 \%$ and granulomatous lesions $40 \%$ which in contrast with $42.72 \%$ and $25.25 \%$ respectively. Prasoon D reported $27.2 \%$ as granulomatous lymphadenitis which matches to our study $(25.25 \%)^{5}$. In the study done by Ahmad S et al, $53.6 \%$ of cases were diagnosed as reactive hyperplasia and $32.8 \%$ as tubercular lymphadenitis. In his study, $46.4 \%$ of cases were AFB positive ${ }^{6}$ whereas in our study $19.2 \%$ of cases were AFB positive. On the other hand, Haque M.A et al found $3.5 \%$ AFB positive cases.

Haque MA et al reported squamous cell carcinoma as the most common metastatic malignancy $(16.6 \%)^{4}$, this very well correlates with our study $(12.62 \%)$. We report $2.9 \%$ lymphoma where as Tilak et al and Egea et al reported $5.6 \%$ and $9.5 \%$ cases of lymphoma respectively in their studies 7,8 .

Breast was the second common site for FNAC. Benign proliferative breast disease was the commonest lesion $(84.1 \%)$ in the age group of 20 to $45 y$ rs. Among malignant lesions, ductal carcinoma was the most common and affected patients above 50 years. Niazi S. et al found that benign breast disease is common (65\%) in younger age group followed by malignancy $(29 \%)$ in 5 th to 6 th decade ${ }^{9}$. This is comparable to our study.

Third common site for FNAC was thyroid gland.
Benign proliferative thyroid disease was the commonest $(47.9 \%)$ which is similar to the result obtained by Matos L.G et al. In his study, benign thyroid lesion comprised $55 \%$ and neoplasm comprised $15 \%{ }^{11}$. Papillary carcinoma was the most common tumor in our study( $11.3 \%$ ) which is also the most common malignant neoplasm in other studies.

Pleomorphic adenoma was the commonest tumor of all primary salivary tumors and parotid gland was the commonest site $(80 \%)$. This tallies with the study conducted by S. Ahamed et al (70\%) .In his study pleomorphic adenoma was the commonest benign tumor( $73 \%$ ) of all primary salivary gland tumor $(73 \%)$. Adenoid cystic carcinoma was the most common malignancy $(35.7 \%)^{12}$ Whereas mucoepidermoid carcinoma and hyalinizing clear cell carcinoma comprised $12.2 \%$ each in our study. The highest incidence for benign lesions was in the 3rd and 4th decade and malignant lesions in 4th to 5th decades of life. S. Ahmad et al observed benign tumors in age group of 30 to 70 years while pick incidence of malignant tumors was 6 th to 7 th decades.

\section{Conclusion}

Wide range of lesions, both benign and malignant, can be diagnosed by FNAC thus restricting surgery to cases only requiring further histopathological evaluation.

\section{References}

1. Svante R O,G regory F.S, Walters M N, Whitaker $D$ : Manual and atlas of fine needle aspiration cytology,3rd edition, Churchill Livingstone 2002: 3-6.

2.Winifred G, Mckee GT, diagnostic Cytopathology, 2nd edition, Churchill Livingstone 2003, 281283.

3. Fine needle aspiration in cancer diagnosis, lan $D$ Buley, BMJ , 2004, J uly 31;329(7460):244-245. 
4. Haque MA, Talukder SI. Evaluation of fine needle aspiration cytology (FNAC) of lymph node in Mymensingh, Mymensingh Med J , 2003 J an; 12 (1): 33-35.

5. Prasoon D. Acid fast bacilli in FNA smears from tuberculous lymph nodes. Acta

cytologica;2000:44:297-300.

6. Ahamd SS, Akhtar S, Akhtar K. Study of fine needle aspiration cytology in lymphadenopathy with special reference tobacid fast in case of tuberculosis. J K Science Vol 7, No. 1; J an-March 2005.

7. Tilak V, Dhadel AV, J ain R. Fine needle aspiration cytology of head and neck masses.

Ind J Path Microbiol 2002;45(1): 23-30 Aspiration biopsy. Acta Cytologica 2002: 46:368-39.
8. Egea AS, Gonzalez NAM et al. Usefulness of light microscopy in lymph node fine needle aspiration.

9. Shahida Niazi, Farukh Kamal: Fine needle aspiration cytology (FNAC); Role in parable breast lesions. The Professionals Vol 7, No. 04, Oct, Nov, Dec. 2004.

10. Godinho M L, Kocjan G., Kurtz A. Contribution of fine needle aspiration cytology to diagnosis and management of thyroid disease. Clin pathol. 1992, May; 45(5): 391-395.

11. S.Ahmad, M. Lateef; R. Ahamd. Clinopathlogical Study of Primary Salivary Gland Tumors in Kashmir. JK practitioner 2002;9(4)231-233. 